\title{
Hydrometeorological relationships on Haig Glacier, Alberta, Canada
}

\author{
J.M. SHEA, ${ }^{*}$ F.S. ANSLOW, S.J. MARSHALL \\ Department of Geography, University of Calgary, 2500 University Drive NW, Calgary, Alberta T2N 1N4, Canada \\ E-mail: jmshea@interchange.ubc.ca
}

\begin{abstract}
We investigate the relationships between meteorological, hydrological and glaciological data collected at Haig Glacier, Alberta, Canada, for the 2002 and 2003 ablation seasons. Correlation, lag cross-correlation and multivariate regression analyses are employed to assess the seasonal evolution of relationships between temperature, temperature residuals, total daily radiation, albedo, accumulationarea ratio (AAR) and total daily discharge $\left(Q_{i}\right)$. Early-season melt is temperature-dependent, when AAR remains high and the hydraulic properties of the snowpack limit both diurnal discharge variability and a rapid hydrologic response. As the melt season progresses, a decreasing AAR and ripening of the snowpack induce a glacier-wide decrease in albedo, and a structured radiation-discharge response is observed. Radiation-detrended temperature values offer modest improvements over physical temperature values in multivariate regression models estimating daily discharge values. Using a detrended-temperature indexed melt model, we assess the transport efficiency of the glacial hydrologic system through a comparison of total modelled daily melt and observed discharge. Transport efficiency values support the notion of a purge effect during freezing events and at the end of the ablation season, and suggest that it is the evolution of the supraglacial drainage system that controls diurnal discharge variability.
\end{abstract}

\section{INTRODUCTION}

Concerns regarding the future viability of water resources in the Canadian Prairies (Demuth and Keller, 1997; Environment Canada, 2004) demonstrate that an improved monitoring network and understanding of processes regulating meltwater generation on alpine glaciers are needed. Glaciohydrological studies in the Canadian Rockies have largely been confined to Peyto Glacier (e.g. Young, 1981; Munro, 1991; Demuth and Pietroniro, 1999), with scattered results from other sites (Rae Glacier: Smith, 1995). Thus, we present initial results and interpretations from a glaciohydrological study on the eastern slopes of the Canadian Rockies with an anticipated long-term monitoring program.

This research aims to (1) quantify relationships between hydrometeorological and glaciological variables and (2) identify surface processes affecting glacier discharge from an alpine glacier in the Canadian Rockies. The relationships between meteorological parameters and meltwater generation have been intensively studied (e.g. Braithwaite, 1995; Hannah and McGregor, 1997; Hannah and others, 2000; Singh and others, 2000; Hodgkins, 2001; Willis and others, 2002). We highlight the work of Singh and others (2000) in particular, due to its use of lag correlation in evaluating relationships between discharge and meteorological parameters. Similar to Jensen and Lang (1973), Singh and others (2000) divided the discharge record into monthly intervals and found that lag times between air temperature and discharge varied throughout the season. One focus of this research is to examine the seasonal evolution of lag correlation relationships, and identify physical processes responsible for the observed changes.

Proglacial discharge from alpine glaciers generally exhibits pronounced increases in daily discharge maximum

*Present address: Department of Geography, University of British Columbia, 1984 West Mall, Vancouver, British Columbia V6T 1Z2, Canada. and range, with superimposed effects from precipitation events and freezing/snowfall occurrences (Meier and Tangborn, 1961; Smith, 1995; Fountain, 1996; Hannah and others, 2000; Willis and others, 2002; Verbunt and others, 2003). A critical issue in this regard is the role of the accumulation-area ratio (AAR) in the regulation of daily discharge range and totals. The AAR is the fraction of snowcovered glacier surface (0-1); changes in the AAR will produce significant changes in glacier-wide radiation reflectance and absorption, with consequences for runoff (Moore and Demuth, 2001). Snow and firn also act as aquifers on a glacier (e.g. Stenborg, 1970), thereby serving to dampen discharge peaks and reduce the amplitude of diurnal flow variability. A decreasing AAR hence supports the rapid hydrological response of ice surfaces which do not store substantial amounts of meltwater, promoting increased diurnal variability. Model results at Haut Glacier d'Arolla, Switzerland, demonstrate that a reduction in AAR leads to a decreased lag between peak melt and peak discharge, and an increase in maximum discharge (Willis and others, 2002). Two processes essential to evaluating seasonal glacier discharge are therefore embedded in the seasonal evolution of the AAR: first, it represents the change in snow/firn/ice partitioning of the surficial drainage network, and secondly, it constrains the average glacier-wide albedo and total absorbed radiation over the glacier surface. This study assesses the effect of snowline retreat, expressed through a modelled AAR, on the measured diurnal discharge of Haig Glacier, and its impact on linear multivariate regression analyses.

\section{FIELD SITE AND DATA SOURCES}

Haig Glacier $\left(50^{\circ} 43^{\prime} \mathrm{N}, 115^{\circ} 18^{\prime} \mathrm{W}\right)$, located approximately $100 \mathrm{~km}$ southwest of Calgary, Alberta, is the largest arm of a small icefield in the Front Ranges of the Canadian Rockies (Fig. 1). Mass-balance and meteorological measurements 


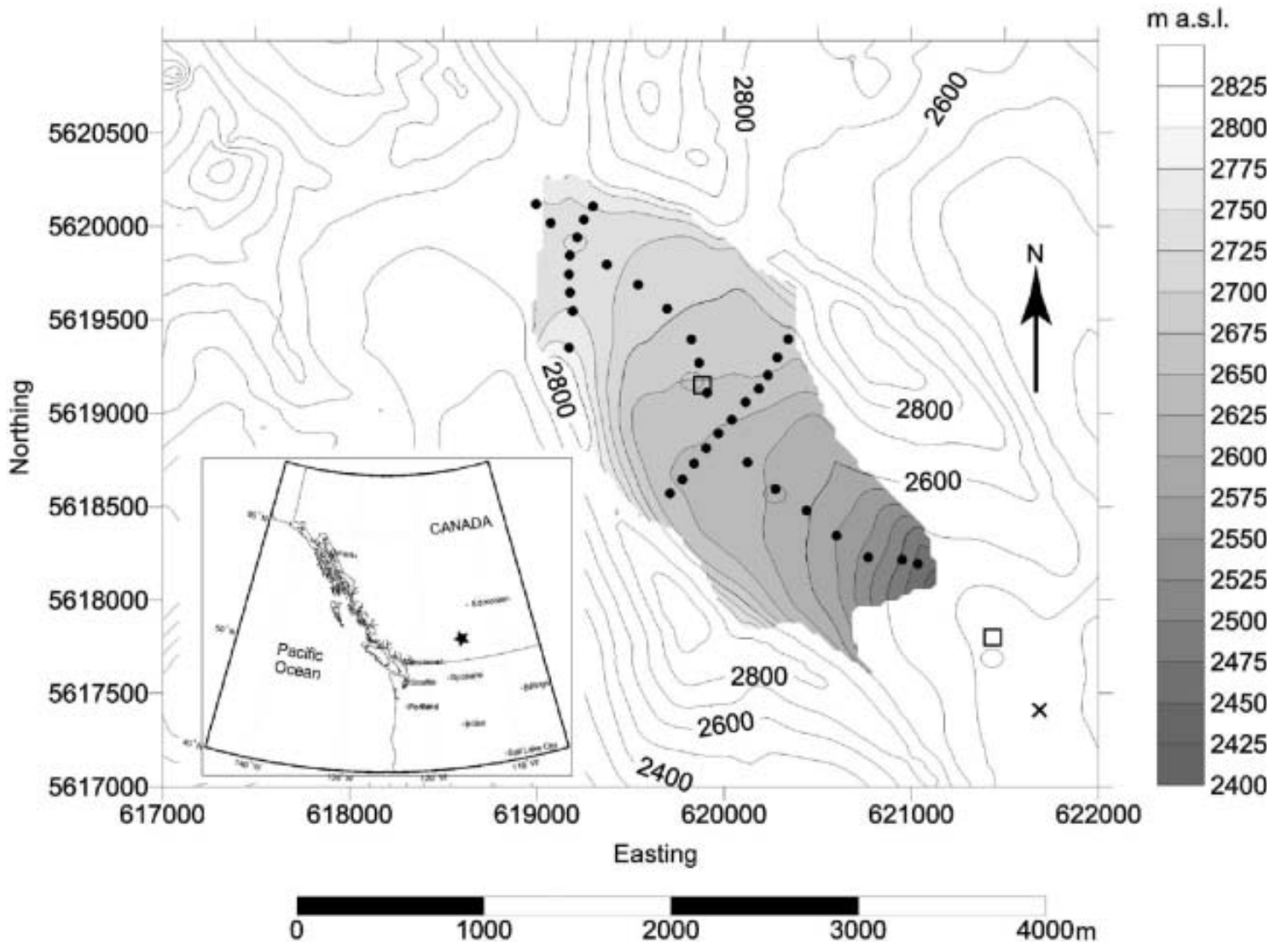

Fig. 1. Study area showing location of Haig Glacier (inset), automatic weather stations (squares), ablation-stake locations (solid dots), massbalance density pits (open circles) and stream gauge $(x)$. Bedrock contours in ma.s.l.

began in 2001 on the southeast arm of Haig Glacier, which has an area of $3.0 \mathrm{~km}^{2}$ and ranges in elevation from $2800 \mathrm{~m}$ at the continental divide to $2450 \mathrm{~m}$ at the toe. The main accumulation zone is a broad, gently sloping plateau located on the Continental Divide, which can receive upwards of $1800 \mathrm{~mm}$ snow water equivalent (SWE) annually. As a result of the low slope angles and modest relief of the glacier, slight variations in the equilibrium-line altitude (ELA) produce major changes in the accumulation area.

In 2002 and 2003, proglacial stream discharge was measured at a site $400 \mathrm{~m}$ downstream from the glacier toe (Fig. 1), where the single proglacial stream is channelized by bedrock. Stage height of the stream was measured with a Campbell Scientific SR-50 ultrasonic depth gauge at $10 \mathrm{~min}$ intervals, and glacial discharge records were calculated from rating curves created for each season from simultaneous stage and discharge measurements. Climate data were captured by two automatic weather stations (AWSs) recording $30 \mathrm{~min}$ averages of $10 \mathrm{~s}$ measurements of temperature, relative humidity, incoming and outgoing solar radiation (spectral range $0.3-2.8 \mu \mathrm{m})$, atmospheric pressure, wind speed and direction, and snow depth. The upper AWS is located along the longitudinal ablation monitoring line, near the midpoint of the glacier at $2640 \mathrm{~m}$ (Fig. 1). The lower AWS is located below the toe of the glacier, roughly midway between the stream gauging site and the glacier terminus. Three weeks of data are missing from the upper AWS in 2003, as forest fires in the area forced an early field evacuation. Missing values at the upper AWS were replaced using regressions with the highly correlated lower-AWS data. Average surface albedo and daily average AAR values are obtained from the melt model developed for Haig Glacier by Anslow (2004) (see Appendix).

\section{METHODS}

Mean daily discharge $\left(Q_{i}\right)$, daily average temperature $(T)$, total daily insolation $(K)$, average daily detrended temperature $\left(D_{\mathrm{t}}\right)$, and standardized discharge range $\left(Q_{\mathrm{sr}}\right)$ are calculated for daily periods from 0000 to $2330 \mathrm{~h}$, with

$$
Q_{\mathrm{sr}}=\frac{Q_{\mathrm{p}}-Q_{\mathrm{b}}}{Q_{\mathrm{b}}},
$$

where $Q_{p}$ is daily peak flow and $Q_{b}$ is daily base flow (Hannah and others, 2000).

A measure of radiation-detrended temperature was constructed by removing that part of the temperature signal that was linearly correlated with incoming solar radiation (Anslow, unpublished information). This provides a time series of 'residual temperature' which physically represents the temperature variability (hence, energy that is available for melt) associated with sensible and longwave heat fluxes. The resultant radiation-detrended temperature series is also independent of incoming solar radiation, avoiding statistical problems that arise due to correlation of solar radiation and actual temperature. It thus provides an estimate of the warming or cooling effects associated with boundary layer inversions, synoptic weather systems (i.e. the sensible-heat flux associated with different air masses), local winds (katabatic or valley winds that affect Haig Glacier) and the infrared radiative balance (e.g. cloudy vs clear-sky conditions). 


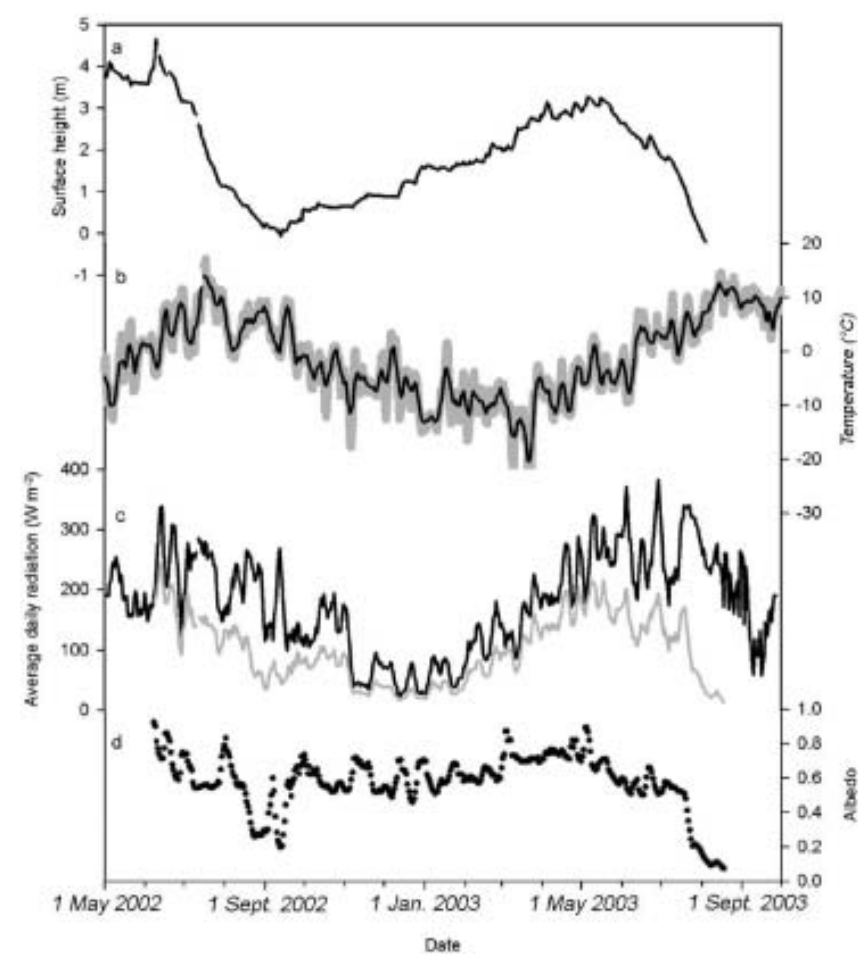

Fig. 2. Summary of upper-AWS meteorological data: (a) daily average surface height (relative to end of summer 2002); (b) 5 day running mean temperature; (c) average daily incoming (dark curve) and outgoing (light curve) shortwave radiation; and (d) 5 day running mean of average daily albedo (calculated between 1000 and $1600 \mathrm{~h}$ ).

We derive time series of daily average AAR and daily average surface albedo for the 2002 and 2003 ablation seasons using a blend of observations and model simulations. Hourly snow- and ice-melt values are simulated for the two seasons using a radiation-detrended temperatureindexed melt model (described in the Appendix and in greater detail by Anslow (2004)), with daily totals calculated between 0000 and $2330 \mathrm{~h}$ during the ablation season.

To investigate seasonal variability of glacial meltwater storage and release, the transport efficiency (TE) of the glacier hydrologic system was calculated using total modelled glacier-wide daily melt $\left(\mathcal{M}_{\mathrm{t}}\right)$ and observed total daily discharge $\left(Q_{\mathrm{t}}\right)$, both in units of $\mathrm{m}^{3}$ :

$$
\mathrm{TE}=\frac{M_{\mathrm{t}}}{Q_{\mathrm{t}}} \times 100 \%
$$

Groundwater inputs and non-glacial snowmelt inputs to the proglacial stream were assumed to be negligible; the proglacial stream flows through a bedrock-incised channel with thin morainal debris, and Haig Glacier is surrounded by steep topography which is typically snow-free during the ablation season. Daily values of TE were examined for the 2003 ablation season, where stream-discharge data were sufficient to permit evaluation of melt-runoff relationships over most of the ablation season.

\section{Statistical analysis}

Analysis of the meteorological and hydrological datasets follows the two main purposes of the paper: lag autocorrelation is used to establish the varying strength of timedependent relationships between radiation, discharge and temperature (Singh and others, 2000); correlations between

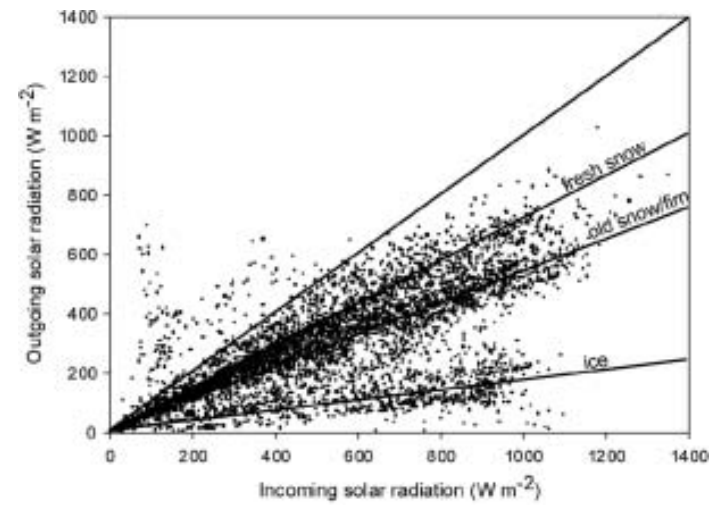

Fig. 3. Scatter plot of half-hour incoming and outgoing solar radiation for points between 1000 and $1600 \mathrm{~h}$, May 2002September 2003.

daily discharge, standardized discharge range, temperature, insolation, albedo and AAR are investigated, and multivariate regression equations are derived to anticipate discharge forecasting from Haig Glacier.

Lag cross-correlation $(r)$ establishes temporal relationships between two time series of data $\left(u_{t}\right.$ and $\left.y_{t}\right)$ through examination of sample cross-variance function $c_{u y}$ and sample variances $c_{u u}(0), c_{y y}(0)$ as a function of lag $(k)$ :

$$
r_{u y}(k)=\frac{c_{u y}(k)}{c_{u u}(0) c_{y y}(0)} .
$$

From the ablation season datasets, half-hour averages of temperature, radiation and discharge were divided into daily windows and 5 day windows to examine the seasonal evolution of the relationships between variables, and identify meteorological events which produce distinct deviations from the expected hydrologic response. Lag periods of up to 8 hours were investigated for both the daily and 5 day windows.

From the time series of mean daily discharge $\left(Q_{i}\right)$, mean previous day's discharge $\left(Q_{i-1}\right)$, mean daily temperature $\left(T_{i}\right)$, total daily insolation $\left(K_{i}\right)$, radiation-detrended temperature (DT) and modelled mean daily AAR, we conduct a suite of linear multivariate regression analyses. Normality of variables entered into a regression analysis was formally examined with the Kolmogorov-Smironov test (Neter and others, 1996). All variables in 2002 passed tests for normality, but in 2003 this was only the case for the detrended temperature dataset.

\section{RESULTS AND DISCUSSION}

Figure 2 displays summaries of the AWS datasets: snow depth, and incoming and outgoing radiation, albedo, and 5 day running means of temperature recorded between May 2002 and September 2003. Mean summer (JuneAugust) temperatures were $5.5^{\circ} \mathrm{C}$ in 2002 and $6.7^{\circ} \mathrm{C}$ in 2003 , and the 2002 melt season was punctuated by several episodes of below-freezing temperatures and minor snowfall events, whereas 5 day running means between 3 June and 9 September 2003 remained above $0^{\circ} \mathrm{C}$. As the snowline retreats past the upper AWS, rapid surface transitions are evident in the albedo record. A scatter plot of incoming and outgoing radiation between 1000 and $1600 \mathrm{~h}$ local time for the entire period (Fig. 3) further reveals distinct albedos for 

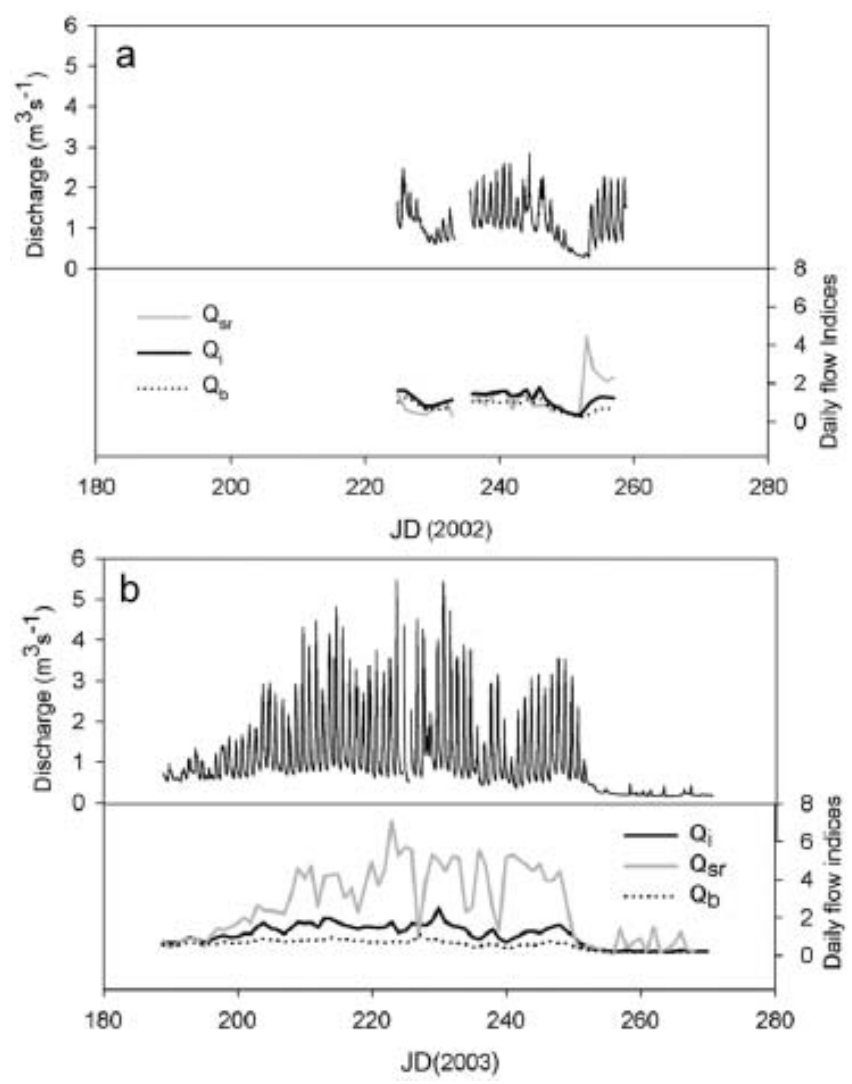

Fig. 4. $30 \mathrm{~min}$ averages of discharge from Haig Glacier proglacial stream (top) and flow indices $Q_{\mathrm{b}}, Q_{\mathrm{sr}}, Q_{\mathrm{i}}$ (bottom) for the 2002 and 2003 ablation seasons.

the three main surface types (fresh snow, aged snow/firn, and bare ice). Points which lie above the theoretical $1: 1$ line, i.e. values in the time series where reflected surface radiation is greater than incoming solar radiation, result from snowfall episodes where the sky-facing pyranometer is covered by snow.

Glacial discharge records, calculated from rating curves created for each season from simultaneous stage and discharge measurements, are shown in Figure 4. Logistical difficulties prevented the full collection of discharge for both seasons; the 2003 discharge record is significantly longer than that of 2002, with most of the ablation season captured in 2003. Differences are evident in the available data from each year, with 2003 demonstrating peak discharges of a much higher magnitude than 2002. Average baseflows calculated for the overlap period in each season show higher baseflows in $2002\left(0.81 \mathrm{~m}^{3} \mathrm{~s}^{-1}\right)$ than in 2003 $\left(0.53 \mathrm{~m}^{3} \mathrm{~s}^{-1}\right)$. In 2003 the dependent variable $Q_{i}$ does not exhibit a normal distribution when all cases are considered. Discharge data for 2003 (Fig. 3) reveal a prominent shift in discharge mode near the end of the season. When the final 19 observed cases are excluded from the discharge dataset, the distribution passed formal normality testing, and significance levels attained in the subsequent trimmed regression analyses are valid. However, we also ran regression analyses with the inclusion of these 19 cases, and present the results in the following subsection for comparison. A significant question here is: does removal of these points increase the statistical strength of the regression model, or should the model be able to specify shut-off periods as well, despite the non-normality of the discharge data? Modelled AAR

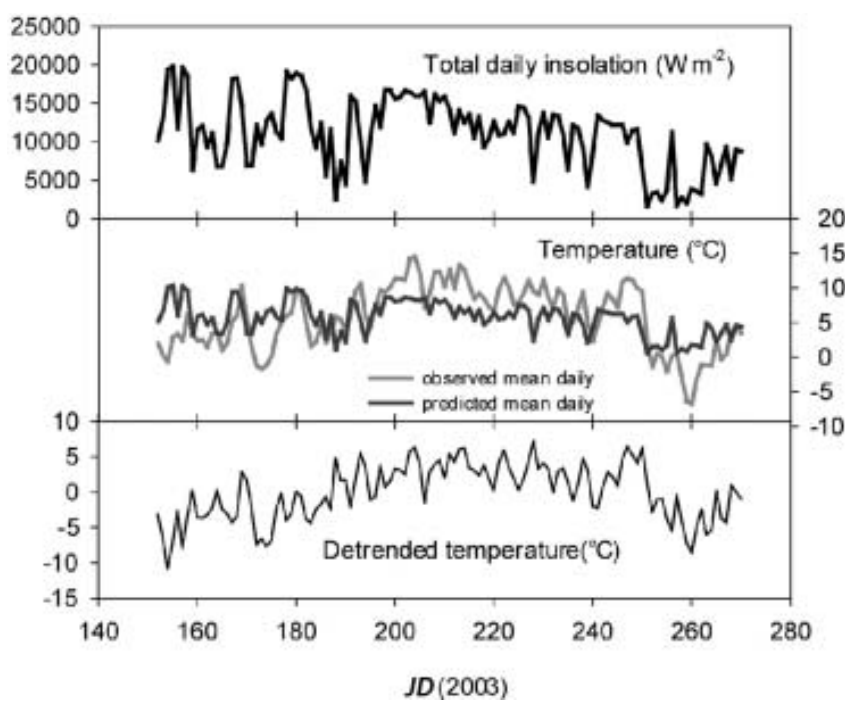

Fig. 5. Radiation, observed temperatures, predicted temperatures and residual values for the 2003 ablation season. A small amount of correlation between the residuals and the radiation series still exists (Table 3).

in 2003 likewise assumes a non-normal distribution; this, however, is a product of the hypsometry of the glacier itself, which leads to rapid changes in AAR when the snowline retreats over low-sloping sections on the upper glacier (Fig. 1). In 2002 this retreat only begins to occur by the end of the ablation season, and consequently the distribution of AAR assumes normality in 2002. As a key point of this investigation, however, we acknowledge the limitation of using non-normally distributed AAR data with regard to establishing significance levels on regression equations.

Glacier mass-balance values derived from ablation-stake surveys during the ablation season and from snow-depth and -density surveys during the accumulation season (cf. Fig. 1) are also substantially different for the two seasons (Table 1 ), 2002/03 being one of the most negative mass-balance years on record in the Canadian Rockies.

Detrended temperature values calculated from the regression of radiation and temperature are presented in Figure 5. The residual values (bottom panel) are entered in the multivariate regression analysis.

\section{Cross-correlation analysis}

Table 2 presents results from lag cross-correlation analysis of 5 day periods of average temperature, radiation and discharge for 2002 and 2003 at half-hour observation periods. Negative lag times indicate that peak discharge leads either temperature or radiation, thereby invalidating a causal relationship. Early-season discharge is more strongly correlated with temperature, yet both seasons evidence a shift to

Table 1. Haig Glacier mass-balance values (mm. w.e.) for 2002 and 2003 mass-balance years

\begin{tabular}{lccr}
\hline & Winter & Summer & Net \\
\hline $2001 / 02$ & 1860 & -2130 & -330 \\
$2002 / 03$ & 1090 & -2660 & -1530 \\
\hline
\end{tabular}


Table 2. Lag cross-correlation $r$ values for discharge vs radiation and temperature in 2002 and 2003 ablation seasons

\begin{tabular}{|c|c|c|c|c|}
\hline \multirow[t]{2}{*}{5 day period } & \multicolumn{2}{|c|}{ Radiation } & \multicolumn{2}{|c|}{ Temperature } \\
\hline & $\begin{array}{l}\text { Maximum } \\
\text { correlation }\end{array}$ & $\begin{array}{c}\text { Lag } \\
\text { hours }\end{array}$ & $\begin{array}{l}\text { Maximum } \\
\text { correlation }\end{array}$ & $\begin{array}{l}\text { Lag } \\
\text { hours }\end{array}$ \\
\hline \multicolumn{5}{|l|}{ JD 2002} \\
\hline $224-228$ & 0.679 & 3.5 & 0.698 & 0.5 \\
\hline $229-233$ & 0.576 & 4.5 & 0.676 & 2.5 \\
\hline $234-238$ & 0.824 & 3 & 0.532 & 0.5 \\
\hline $239-243$ & 0.917 & 2.5 & 0.614 & -0.5 \\
\hline $244-248$ & 0.14 & 1.5 & 0.719 & 1 \\
\hline $249-253$ & 0.748 & 4 & 0.695 & 2 \\
\hline \multicolumn{5}{|l|}{ JD 2003} \\
\hline 189-193 & 0.579 & 6.5 & 0.731 & 4 \\
\hline 194-198 & 0.715 & 5 & 0.731 & 1.5 \\
\hline 199-203 & 0.825 & 3.5 & 0.805 & 0.5 \\
\hline 204-208 & 0.937 & 3 & 0.645 & -0.5 \\
\hline 209-213 & 0.931 & 3 & 0.681 & -1 \\
\hline $214-218$ & 0.891 & 2 & 0.618 & -2 \\
\hline $219-223$ & 0.859 & 2.5 & 0.562 & -0.5 \\
\hline $224-228$ & 0.85 & 3 & 0.551 & 0 \\
\hline $229-233$ & 0.88 & 3 & 0.714 & -1 \\
\hline $234-238$ & 0.776 & 4 & 0.636 & 0 \\
\hline $239-243$ & 0.805 & 5 & 0.619 & -0.5 \\
\hline $244-248$ & 0.815 & 4 & 0.611 & -1.5 \\
\hline $249-253$ & 0.827 & 2.5 & 0.722 & 1 \\
\hline $254-258$ & -0.18 & 2 & -0.305 & 1 \\
\hline $259-263$ & 0.702 & -5 & -0.401 & 2 \\
\hline $264-268$ & 0.381 & -5 & -0.275 & 1.5 \\
\hline
\end{tabular}

Notes: A negative lag value indicates that peak discharge occurs before radiation or temperature, thereby invalidating a causal relationship. Of temperature- and radiation-discharge correlations, the strongest periodic correlation is placed in bold to emphasize seasonal evolution of relationships. All correlations are significant at $p=0.05, n=239$.

radiation-dominated discharge regimes by mid-summer. Snowfall events in 2002 (Julian days (JD) 244-248) and 2003 (JD 254-258) have a remarkable effect, causing the radiation-discharge correlation to collapse.

Radiation-discharge lag times in 2003 decrease to 2.5 hours by JD 219-223, yet increase to 5 hours by JD 239-243, with no precipitation recorded during this period. A subsequent increase in lag time (JD 239-243) is the consequence of either an evolving glacier surface or a switch in subglacial drainage from a fast (channelized) to a slow (distributed) drainage network (Nienow and others, 1996; Gordon and others, 1998; Willis and others, 2002). A crevasse zone in the bottom third of Haig Glacier offers numerous pathways for the quick transfer of melt from the surface to the subglacial drainage system. As the snowline retreats above this zone, melt is either distributed into upglacier moulins with a longer subglacial routing, or travels along the surface to the lower crevasse zone, effectively increasing the lag time between peak radiation and discharge. Moulin development has been observed late in the ablation season, perhaps explaining the subsequent decrease in lag times that occurs on JD 249-253.

These observations from 5 day lag periods are borne out by an examination of daily lag cross-correlations (Fig. 6). The short duration of the 2002 discharge record prevents indepth interpretation, yet compared with the 2003 daily
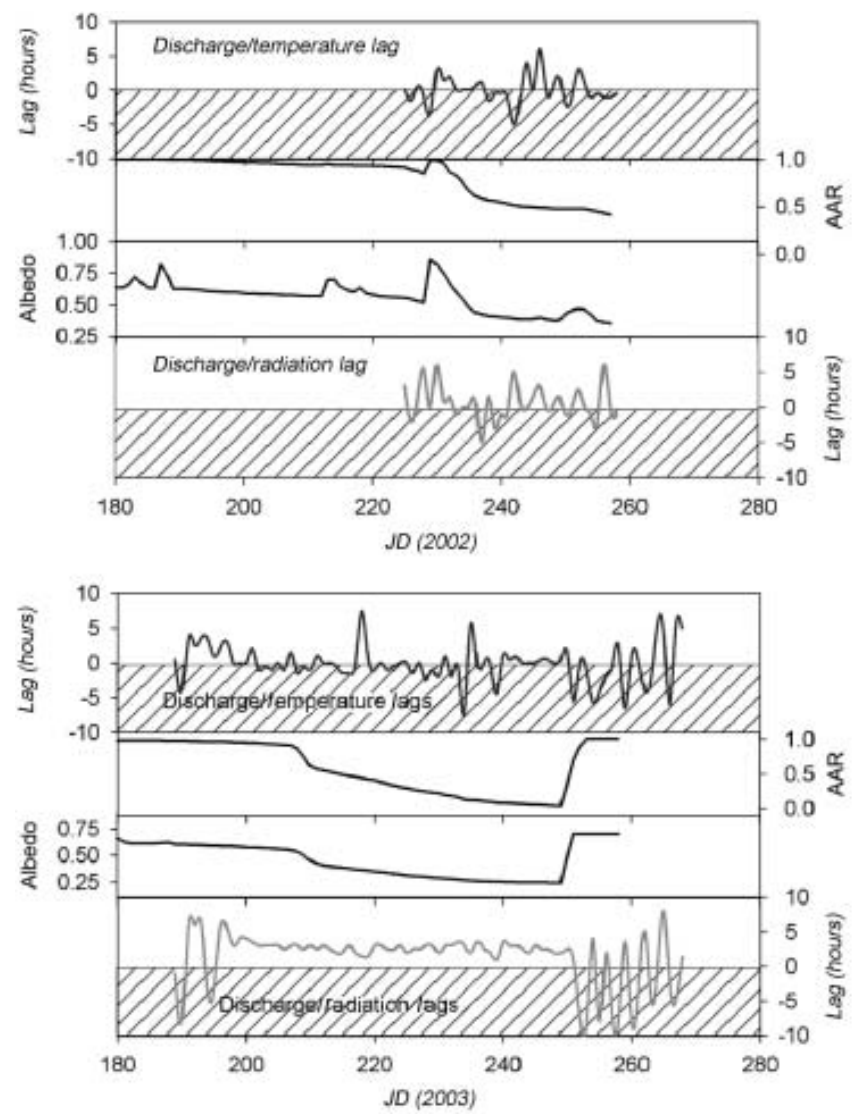

Fig. 6. Daily lag/lead for temperature, radiation and discharge, 2002 and 2003 ablation seasons, with plotted glacier average albedo and AAR. Shaded areas indicate that discharge leads the variable in question (hence the relationship is null).

cross-correlation record, the lack of a structured dominance of either radiation or temperature in 2002 presents the idea that AAR is an influential factor in discharge responses. In the 2003 record, the switch from a variable lag pattern to one of structured radiation-dominated discharge with a lag of approximately 2.5-3 hours occurs early in the record, when AAR values are still high. This is interpreted as either the establishment of a surface-bed connection, as crevasses in the lower part of the glacier are now open and draining snowpack runoff to the glacier bed (cf. Fountain, 1996), or possibly the switch from a distributed subglacial network to one that is channelized. As the season progresses, fluctuations in daily lag pattern are consistent with varying incoming solar radiation inputs and a decreasing AAR, which gradually shortens the observed daily lag between peak radiation and peak discharge. The snowfall observed on JD 251 (AAR $=1$ ) coincides with a return to the variable lag pattern, and thus a return to multi-day or variable discharge response. In 2002 the radiation-dominated discharge response is not observed, as a deep winter snowpack delayed the spring melt, and summer snowfall events disrupted the development of the supraglacial drainage system which was observed in 2003.

\section{Single-variate correlation analysis}

Results from univariate correlation analysis of $Q_{i}, Q_{i-1}, T_{i}$ $K_{i}, \mathrm{AAR}, Q_{\mathrm{sr}}$ and DT are presented in Table 3. Strongest seasonal correlations are observed between $Q_{i}$ and $Q_{i-1}$, with strong correlations also existing between daily average 
temperatures and discharge. Detrended temperature values offer an even stronger correlation with discharge than temperature itself, and so are preferentially employed in the multivariate regression analysis. Daily radiationdischarge correlations are comparatively lower than temperature-discharge correlations. In 2002, the greater winter mass balance (Table 1), lower summer temperatures and multiple summer snowfalls (Fig. 2) led to a low snowline position through much of the ablation season (cf. Fig. 6). The resultant high albedo reduced the efficiency of radiation in the daily production of meltwater, while higher baseflows resulted from meltwater storage and refreezing in the snow/ firn aquifer (Willis and others, 2002) that covered a large area of the glacier through the ablation season. Fountain (1996) suggested that an observed seasonal increase in diurnal streamflow variation is the product of faster flow routing at the glacier surface, rather than an enlargement and increased efficiency of the subglacial hydraulic system (cf. Nienow and others, 1996; Willis and others, 2002). Low AAR values that persist through the 2003 season contribute to a much stronger AAR- $S_{\text {qr }}$ correlation, and the timing of an increase in $Q_{\mathrm{sr}}$ coincides with rapidly decreasing AAR and albedo values. Correlations between AAR and standardized discharge range are negative and significant in both 2002 and 2003 ( -0.39 and -0.67 , respectively), suggesting that the surficial evolution is a strong contributing factor to the observed diurnal discharge.

\section{Linear multivariate regression analysis}

A suite of linear multivariate regression analyses for both ablation seasons is presented in Table 4. Regressions are generally more robust in 2003, though caution is warranted due to the non-normality of the AAR dataset. Below are listed several key observations regarding the multivariate regression analyses:

1. The inclusion of all cases in 2003 regression analyses improves the regression results substantially. We suggest that as a regressive model, the performance is optimized when the model can accurately specify melt shut-down points through temperature and radiation data. An exploration of non-parametric regression methods is suggested as a way of surmounting this obstacle.

2. $T$ and DT regressions against $Q_{i}$ produce inconclusive results, with a stronger regression from the detrended temperature values in 2003, and weaker regression in 2002. Note, however, that the use of DT values increases the Durbin-Watson score in both seasons. While the improved scores still demonstrate a high degree of autocorrelation, with the addition of multiple predictor variables the temperature data continue to cause an autocorrelation issue in the regression results. The use of detrended temperature data eliminates autocorrelation in these multivariate analyses, and is furthermore a normally distributed dataset in both seasons.

3. Using the previous day's discharge, all regressions are improved substantially and autocorrelation is eliminated. Models without this term still perform robustly, and additionally offer the possibility of predicting glacier discharge using remotely sensed or commonly measured data (AAR, DT and $K$ ). Preferred models, according to criteria of normality and robustness, are shown in Table 4.
Table 3. 2002 and 2003 ablation season correlation matrix for average discharge $\left(Q_{i}\right)$, average daily temperature $(T)$, total daily insolation $\left(K_{\mathrm{t}}\right), \mathrm{AAR}$, daily detrended temperature (DT), daily standardized discharge range $\left(S_{\mathrm{qr}}\right)$ and previous day's average discharge $\left(Q_{i-1}\right)$

\begin{tabular}{|c|c|c|c|c|c|c|c|c|}
\hline & & $Q_{i}$ & $T$ & $K$ & AAR & DT & $S_{\mathrm{qr}}$ & $Q_{i-1}$ \\
\hline \multicolumn{9}{|l|}{2002} \\
\hline \multirow[t]{2}{*}{$Q_{i}$} & $r$ & 1 & & & & & & \\
\hline & $N$ & 31 & & & & & & \\
\hline \multirow[t]{2}{*}{$T$} & $r$ & 0.617 & 1 & & & & & \\
\hline & $N$ & 29 & 32 & & & & & \\
\hline \multirow[t]{2}{*}{ K } & $r$ & 0.283 & 0.739 & 1 & & & & \\
\hline & $N$ & 26 & 28 & 28 & & & & \\
\hline \multirow[t]{2}{*}{ AAR } & $r$ & 0.01 & 0.229 & 0.306 & 1 & & & \\
\hline & $N$ & 31 & 31 & 28 & 33 & & & \\
\hline \multirow[t]{2}{*}{ DT } & $r$ & 0.738 & 0.786 & 0.164 & 0.139 & 1 & & \\
\hline & $N$ & 26 & 28 & 28 & 28 & 28 & & \\
\hline \multirow[t]{2}{*}{$S_{\mathrm{qr}}$} & $r$ & 0.168 & 0.492 & 0.621 & -0.386 & 0.183 & 1 & \\
\hline & $N$ & 31 & 29 & 26 & 31 & 26 & 31 & \\
\hline \multirow[t]{2}{*}{$Q_{i-1}$} & $r$ & 0.773 & 0.271 & 0.038 & 0.002 & 0.478 & -0.186 & 1 \\
\hline & $N$ & 29 & 28 & 25 & 30 & 25 & 29 & 30 \\
\hline \multicolumn{9}{|l|}{2003} \\
\hline \multirow[t]{2}{*}{$Q_{i}$} & $r$ & 1 & & & & & & \\
\hline & $N$ & 63 & & & & & & \\
\hline \multirow[t]{2}{*}{$T$} & $r$ & 0.663 & 1 & & & & & \\
\hline & $N$ & 63 & 63 & & & & & \\
\hline \multirow[t]{2}{*}{$K$} & $r$ & 0.304 & 0.569 & 1 & & & & \\
\hline & $N$ & 63 & 63 & 63 & & & & \\
\hline \multirow[t]{2}{*}{ AAR } & $r$ & -0.307 & 0.156 & 0.281 & 1 & & & \\
\hline & $N$ & 63 & 63 & 63 & 63 & & & \\
\hline \multirow[t]{2}{*}{ DT } & $r$ & 0.557 & 0.751 & -0.116 & -0.037 & 1 & & \\
\hline & $N$ & 63 & 63 & 63 & 63 & 63 & & \\
\hline \multirow[t]{2}{*}{$S_{\mathrm{qr}}$} & $r$ & 0.557 & 0.127 & 0.201 & -0.669 & -0.008 & 1 & \\
\hline & $N$ & 63 & 63 & 63 & 63 & 63 & 63 & \\
\hline \multirow[t]{2}{*}{$Q_{i-1}$} & $r$ & 0.789 & 0.371 & 0.006 & -0.339 & 0.438 & 0.402 & 1 \\
\hline & $N$ & 62 & 62 & 62 & 62 & 62 & 62 & 62 \\
\hline
\end{tabular}

4. Table 5 shows a comparison of coefficient regression equations obtained in our study with those from other sites. Though it is not our preferred model, the strength of the relationships remains high, and coefficients are actually similar to those obtained at Mikkiglaciaren, Sweden (Stenborg, 1970). Preferred model coefficients are presented in Table 6, and interseasonal comparisons show that coefficients remain relatively stable, though the importance of AAR is emphasized in 2003 models.

\section{Transport efficiency analysis}

The TE (Fig. 7), which describes the percentage of daily modelled melt that is captured by daily discharge measurement (Equation (2)), exhibits a long-term increase through the ablation season, and again this is matched by a decrease in the AAR, further suggesting the impact of snow/ice/firn partitioning on diurnal flow variability from an alpine glacier (Willis and others, 2002). The TE record becomes dominated by values greater than $100 \%$ around JD 230, roughly the timing of the observed disappearance of a saturated 'slush' zone from mid-glacier. Precipitation events are superimposed on the overall increasing trend, and can lead to TE $>100 \%$ in some cases (e.g. JD 190, 195 and 237). Most notable in the TE record is the 'purging' of englacial and subglacial melt storage, as a snowfall event and negative 
Table 4. Multivariate regression summary

\begin{tabular}{|c|c|c|c|c|c|c|}
\hline \multirow{3}{*}{ Dataset } & \multirow{3}{*}{ Predictor variables } & \multirow{3}{*}{$R^{2}$} & \multicolumn{4}{|c|}{ Autocorrelation } \\
\hline & & & SE & $\mathrm{D}-\mathrm{W}$ & Decision & Collinearity \\
\hline & & & \multicolumn{4}{|l|}{$\mathrm{m}^{3} \mathrm{~s}^{-1}$} \\
\hline All cases & DT & 0.545 & 0.273 & 1.15 & yes & no \\
\hline All cases & $T$ & 0.38 & 0.315 & 0.7 & yes & no \\
\hline All cases & $\mathrm{DT}, K$ & 0.574 & 0.271 & 0.85 & yes & no \\
\hline All cases & $\mathrm{DT}, K, \mathrm{AAR}, Q_{i-1}$ & 0.796 & 0.198 & 2.25 & no & slight \\
\hline
\end{tabular}

2003 model summary

Dataset

Model variables

$R^{2}$

SE

D-W

Autocorrelation

$\mathrm{m}^{3} \mathrm{~s}^{-1}$

Decision

Collinearity

\begin{tabular}{|c|c|c|c|c|c|c|}
\hline Trim & DT & 0.310 & 0.325 & 0.690 & yes & no \\
\hline Trim & $T$ & 0.426 & 0.297 & 0.480 & yes & no \\
\hline Trim & $\mathrm{DT}, K$ & 0.448 & 0.293 & 0.526 & yes & no \\
\hline Trim & $\mathrm{DT}, K, \mathrm{AAR}$ & 0.613 & 0.248 & 0.734 & yes & no \\
\hline Trim & $\mathrm{DT}, K, \mathrm{AAR}, Q_{i-1}$ & 0.807 & 0.174 & 1.800 & no & no \\
\hline All & DT & 0.535 & 0.338 & 0.890 & yes & no \\
\hline All & $T$ & 0.717 & 0.304 & 0.500 & yes & no \\
\hline All & $\mathrm{DT}_{\mathrm{t}}, K$ & 0.672 & 0.286 & 0.557 & yes & no \\
\hline All & $\mathrm{DT}, K, \mathrm{AAR}$ & 0.759 & 0.241 & 0.708 & yes & no \\
\hline All & $\mathrm{DT}, K, \mathrm{AAR}, Q_{i-1}$ & 0.870 & 0.176 & 1.690 & no & no \\
\hline
\end{tabular}

Notes: A standard error (SE) of $20000 \mathrm{~m}^{3}$ is approximately $10 \%$ of average daily flow. Dependent variable is mean daily discharge $\left(Q_{i}\right)$. Predictors: $T=$ mean daily temperature, $K_{i}=$ total daily incoming solar radiation, $\mathrm{AAR}=$ accumulation-area ratio, $\mathrm{DT}=$ detrended temperature residual, $Q_{i-1}=$ previous day's total discharge. Trim dataset in 2003 is all cases minus the final 19 cases of the discharge record. D-W is the Durbin-Watson statistic, with decision of autocorrelation based on number of cases and variables in analysis. Collinearity decision is based on condition indices of eigenvalues (not shown). All variables assume normal distributions in 2002; in 2003 only DT and $Q_{i(\text { trim })}$ are normal.

temperatures (JD 251) effectively shut off modelled melt, resulting in high transport efficiencies as actual discharge drops off at a slower pace. Stenborg (1970) also observed the delayed flow in the early part of the ablation season, but saw evidence for a major evacuation of stored water in midseason, with a switch to closely matching observed discharge and modelled melt by the end of the ablation season.

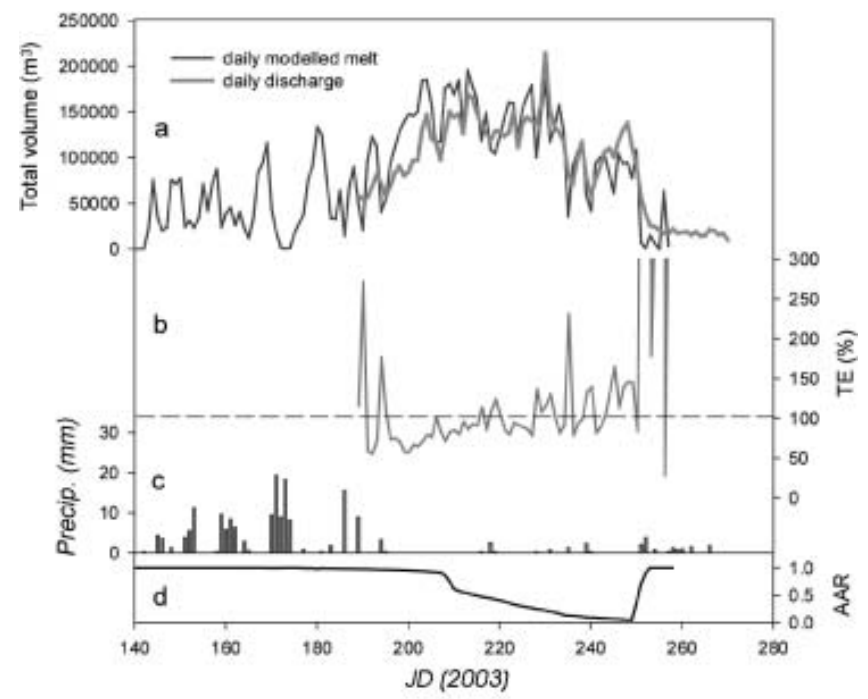

Fig. 7. (a) Total daily modelled melt and total daily discharge; (b) transport efficiency; (c) daily precipitation total; and (d) AAR.
Available evidence from Haig Glacier points towards the evolution of the supraglacial drainage system as the leading control on the observed variability in proglacial discharge values. To corroborate this statement, the subglacial hydrology would need to be evaluated via dye-tracing experiments (e.g. Nienow and others, 1996) or borehole observations (e.g. Fountain, 1996; Gordon and others, 1998).

\section{CONCLUSIONS}

We present glaciological and hydrometeorological relationships determined through correlations, multivariate regressions and lag cross-correlations of total daily discharge $\left(Q_{i}\right)$ vs total daily incoming solar radiation $\left(K_{i}\right)$, average daily temperature $(T)$, average daily temperature residual (DT) and AAR. We also explore the idea of transport efficiency. Evolution of the ablation seasons shows a shift from temperature-dominated to radiation-dominated discharge as the AAR decreases, leading to (i) a decrease in snow and firn cover and associated water storage and (ii) increased absorption of solar radiation. Standardized daily discharge range is strongly correlated to the AAR, as increased ice exposure signifies increased efficiency of the glacier surface hydrology.

Previous day's discharge, detrended temperature and AAR present the strongest seasonal correlations for discharge, and linear multiple regression models offer insight into hydrometeorological relationships. Detrended temperature values decrease autocorrelation in regression analysis, and present normal distributions where temperature datasets might not. The strength of the relationships between 
Table 5. Comparison of ablation season multivariate regression coefficients, with regression coefficient $\left(R^{2}\right)$ and standard error (SE)

\begin{tabular}{|c|c|c|c|}
\hline Site & Equation & $R^{2}$ & SE \\
\hline Dokriani glacier, Garhwal Himalaya, India (Singh and others, 2000) & $Q_{i}=-0.671+0.901 Q_{i-1}+0.125 T_{i}+K_{i}$ & 0.903 & 0.791 \\
\hline Mikkiglaciaren, Sweden (Stenborg, 1970)* & $Q_{i}=0.329+0.546 Q_{i-1}+0.035 \sum T_{+}+0.0014 K_{i}$ & 0.810 & 0.170 \\
\hline Haig Glacier (this study) & $Q_{i}=0.386+0.630 Q_{i-1}+0.041 T_{i}+0.0002 K_{i}$ & 0.868 & 0.183 \\
\hline
\end{tabular}

*Stenborg (1970) used the daily sum of positive temperatures $\left(\sum \mathrm{T}_{+}\right)$and radiation in units of Langley $\mathrm{d}^{-1}$.

Table 6. Summary of preferred regression model coefficients for constant $(b)$ detrended temperature $\left(b_{\mathrm{DT}}\right)$, radiation $\left(b_{K}\right), \mathrm{AAR}\left(b_{\mathrm{AAR}}\right)$ and previous day's mean discharge $\left(b_{Q_{i-1}}\right)$. For comparison between ablation seasons, the same regression models for 2002 and 2003 are shown sequentially

\begin{tabular}{|c|c|c|c|c|c|c|}
\hline Year & Model variables & $b$ & $b_{\mathrm{DT}}$ & $b_{K}$ & $b_{\mathrm{AAR}}$ & $b_{Q_{i-1}}$ \\
\hline 2002 & $\mathrm{DT}, K, \mathrm{AAR}$ & 0.979 & 0.124 & $1.874 \times 10^{-5}$ & -0.074 & \\
\hline 2003 (trimmed) & DT, $K$, AAR & 0.582 & 0.101 & $5.514 \times 10^{-5}$ & -0.464 & \\
\hline 2003 (all) & $\mathrm{DT}, K, \mathrm{AAR}$ & 0.684 & 0.091 & $4.769 \times 10^{-5}$ & -0.423 & \\
\hline 2002 & $\mathrm{DT}, K, \mathrm{AAR}, Q_{i-1}$ & 0.329 & 0.081 & $1.844 \times 10^{-5}$ & 0.032 & 0.536 \\
\hline 2003 (trimmed) & $\mathrm{DT}, K, \mathrm{AAR}, Q_{i-1}$ & -0.005 & 0.059 & $4.309 \times 10^{-5}$ & -0.224 & 0.562 \\
\hline 2003 (all) & $\mathrm{DT}, K, \mathrm{AAR}, Q_{i-1}$ & 0.160 & 0.048 & $3.197 \times 10^{-5}$ & -0.157 & 0.546 \\
\hline
\end{tabular}

discharge, temperature and AAR suggest portability of the discharge regression model to other alpine sites, though these relationships must depend in some part on the crevasse/moulin configurations of a particular glacier and the hypsometry, which will affect AAR values as the snowline retreats.

In conclusion, the results of this study may provide direction for current melt modelling efforts. The use of a detrended temperature series offers a way of eliminating the collinearity of radiation and temperature for multivariate regression models while simultaneously reducing the autocorrelation of a regressed time series. Previous day's discharge is a strong predictor variable for glacial discharge, and the autocorrelation of the discharge time series is indicative of the non-stationarity of the discharge system. We use a modelled AAR variable and radiation-detrended temperature to provide a robust independent variable for discharge predictions. While AAR provides an indirect measure of average glacier albedo, it contains additional information that pertains to delays in runoff associated with the supraglacial snow and firn aquifer. AAR therefore represents a bulk parameter indirectly measuring the glacier-scale supraglacial drainage efficiency.

Most features of the daily and seasonal evolution of runoff at Haig Glacier can be attributed to evolution of the supraglacial drainage system and surface energy balance through the ablation season. The extent of the winter snowpack and the frequency of summer snowfalls proved very important to the drainage-system evolution and the total runoff from this glacier in the 2002 and 2003 ablation seasons. These effects can be broadly captured in runoff modelling through inclusion of AAR and average glacier albedo indices (via $K$ ) in a multivariate regression, accelerating efforts to develop improved hydrological forecasts and runoff models from glaciers of the eastern slopes of the Canadian Rockies. Meltwater runoff from glacierized catchments in the region is an important component of the hydrological budget in the drought-prone southern Canadian prairies.

\section{ACKNOWLEDGEMENTS}

The authors express their gratitude to R. Smith and numerous field assistants. This work was also made possible by funding from the Natural Sciences and Engineering Research Council, Canada, (PGS-A to J. Shea; operating grants to S. Marshall) and the US National Science Foundation, a current-meter loan from R. Rogalski, logistical support from T. Holland and the Canadian Olympic Development Association, and S. Donelon of Alberta Sustainable Development. Two anonymous reviewers provided immensely helpful comments on the original manuscript.

\section{REFERENCES}

Anslow, F.S. 2004. Development and testing of a temperature and radiation based melt model for glaciers in the Canadian Rockies. (MSc thesis, University of Calgary.)

Braithwaite, R.J. 1995. Positive degree-day factors for ablation on the Greenland ice sheet studied by energy-balance modelling. J. Glaciol., 41(137), 153-160.

Brock, B.W., I.C. Willis and M.J. Sharp. 2000. Measurement and parameterization of albedo variations at Haut Glacier d'Arolla, Switzerland. J. Glaciol., 46(155), 675-688.

Demuth, M.N. and R. Keller. 1997. An assessment of the mass balance of Peyto Glacier (1966-1995) and its relation to recent and past-century climatic variability. In Demuth, M.N., D.S. Munro and G.J. Young, eds. Peyto Glacier: one century of science. Saskatoon, Sask., Environment Canada. National Hydrology Research Institute, 83-132.

Demuth, M. and A. Pietroniro. 1999. Inferring glacier mass balance using RADARSAT: results from Peyto Glacier, Canada. Geogr. Ann., 81A(4), 521-540.

Environment Canada. 2004. Threats to water availability in Canada. Burlington, National Water Research Institute.

Fountain, A.G. 1996. Effect of snow and firn hydrology on the physical and chemical characteristics of glacier runoff. Hydrol. Process., 10, 509-521.

Gordon, S., M. Sharp, B. Hubbard, C. Smart, B. Ketterling and I. Willis. 1998. Seasonal reorganization of subglacial drainage inferred from measurements in boreholes. Hydrol. Process., 12, 105-133. 
Hannah, D.M. and G.R. McGregor. 1997. Evaluating the impact of climate on snow- and ice-melt dynamics in the Taillon basin, French Pyrénées. J. Glaciol., 43(145), 563-568.

Hannah, D.M., B.P.G. Smith, A.M. Gurnell and G.R. McGregor. 2000. An approach to hydrograph classification. Hydrol. Process., 14(2), 317-338.

Hock, R. 1999. A distributed temperature-index ice- and snowmelt model including potential direct solar radiation. J. Glaciol., 45(149), 101-111.

Hodgkins, R. 2001. Seasonal evolution of meltwater generation, storage and discharge at a non-temperate glacier in Svalbard. Hydrol. Process., 15, 441-460.

Jensen, $\mathrm{H}$. and $\mathrm{H}$. Lang. 1973. Forecasting discharge from a glaciated basin in the Swiss Alps. International Association of Hydrological Sciences Publication 107 (UNESCO-WMO-IAHS Symposia - The Role of Snow and Ice in Hydrology), 1047-1057.

Kane, D.L., R.E. Gieck and L.D. Hinzman. 1997. Snowmelt modeling at small Alaskan Arctic watershed. ASCE J. Hydrol. Eng., 2(4), 204-210.

Meier, M.F. and W.V. Tangborn. 1961. Distinctive characteristics of glacier runoff. U.S. Geol. Surv. Prof. Pap. 424-B, B14-B16.

Moore, R.D. and M.N. Demuth. 2001. Mass balance and streamflow variability at Place Glacier, Canada in relation to recent climate fluctuations. Hydrol. Process., 15, 3472-3486.

Munro, D.S. 1991. A surface energy exchange model of glacier melt and net mass balance. Int. J. Climatol., 11(6), 689-700.

Neter, S., W. Wasserman, M. Kutner and C.J. Nachtseim. 1996. Applied linear statistical models. Toronto, McGraw-Hill.

Nienow, P., M. Sharp and I. Willis. 1996. Temporal switching between englacial and subglacial drainage pathways: dye tracer evidence from the Haut Glacier d'Arolla, Switzerland. Geogr. Ann., 78A(1), 51-60.

Singh, P., K.S. Ramasastri, N. Kumar and A. Manohar. 2000. Correlations between discharge and meteorological parameters and runoff forecasting from a highly glacierized Himalayan basin. Hydrol. Sci. J., 45(5), 637-652.

Smith, D.J. 1995. Hydrological behaviour of Rae Glacier, Canadian Rocky Mountains. In Guy, B. and J. Barnard, eds. Mountain hydrology: peaks and valleys in research applications. Cambridge, Ont., Canadian Water Resources Association, 113-121.

Stenborg, T. 1970. Delay of run-off from a glacier basin. Geogr. Ann., 52A(1), 1-30.

Verbunt, M.J., J. Gurtz, K. Jasper, H. Lang, P. Warmerdam and M. Zappa. 2003. The hydrological role of snow and glaciers in alpine river basins and their distributed modelling. J. Hydrol., 282(1-4), 36-55.

Willis, I., N. Arnold and B. Brock. 2002. Effect of snowpack removal on energy balance, melt and runoff in a small supraglacial catchment. Hydrol. Process., 16(14), 2721-2749.

Young, G.J. 1981. The mass balance of Peyto Glacier, Alberta, Canada, 1965 to 1978. Arct. Alp. Res., 13(3), 307-318.

\section{APPENDIX}

\section{MELT MODEL DESCRIPTION}

Daily albedo and surface melt totals were modelled using a new temperature and radiation index model fully described by Anslow (2004), which addresses the need for a simple yet physically based ablation model for alpine glaciers. The model was developed following the success of Hock's (1999) model and is similar to that of Kane and others (1997), but addresses the high collinearity of temperature and solar radiation records. This relationship between the two variables argues against utilizing a linear combination of temperature and solar radiation to compute melt, so a means of separating the two records was found. This is accomplished by extracting the variance of the temperature record that is due to solar radiation from the temperature record. Solar radiation is regressed on temperature measured at the glacier AWS using a 3.5 hour time lag - timing of peak correlation between the temperature and radiation records. Before deconvolution, the temperature and radiation records were correlated at 0.40 , whereas the correlation dropped to 0.09 between the residual temperature and incoming solar radiation. The residual between the temperature predicted by the regression and the measured temperature record is then used in the ablation model.

The ablation model takes the form:

$$
M=C_{1} \cdot \int_{t_{0}}^{t_{\mathrm{f}}} T_{\text {resid }} \mathrm{d} t+C_{2} \cdot \int_{t_{0}}^{t_{\mathrm{f}}} K_{\text {netsw }} \mathrm{d} t,
$$

where $T_{\text {resid }}$ is residual temperature as described above in ${ }^{\circ} \mathrm{C}, C_{1}$ is a coefficient with units $\mathrm{m}$ w.e. ${ }^{\circ} \mathrm{C}^{-1} \mathrm{~s}^{-1}$ relating residual temperature totals to ablation, $K_{\text {netsw }}$ is absorbed solar radiation in $\mathrm{W} \mathrm{m}^{-2}, C_{2}$ is a coefficient relating radiation totals to ablation with units $\mathrm{m}$ w.e. $\mathrm{m}^{2} \mathrm{~J}^{-1}, t_{0}$ and $t_{\mathrm{f}}$ are limits of integration spanning the model time-step of $1800 \mathrm{~s}$ (30 min) and $M$ is computed melt in units of meters.

The coefficients in the model were found by tuning to stake ablation measurements (cf. Fig. 1), and the optimum values found were $3.6 \mathrm{~m}^{\circ} \mathrm{C}^{-1} \mathrm{~s}^{-1}$ for $C_{1}$ and $2.78 \times$ $10^{-6} \mathrm{~m}$ w.e. $\mathrm{m}^{2} \mathrm{~J}^{-1}$ for $C_{2}$. Coefficient $C_{2}$ differs from the theoretical value used in energy-balance models, $2.98 \times$ $10^{-6} \mathrm{~m}$ w.e. $\mathrm{m}^{2} \mathrm{~J}^{-1}$, which is determined from the density and latent heat of fusion of water. This discrepancy is likely due to the incomplete extraction of solar-radiation induced variance from the temperature record as indicated by the correlation of 0.09 between the residual and the solar radiation record mentioned above. It is also notable that this model places no restriction on the sign of the temperature residual used to compute melt. A negative residual indicates that air temperatures are playing a cooling role relative to the radiation values measured at the time. Positive residual temperatures occur during times when temperature must account for ablation beyond that which is explainable by net solar radiation. The model still imposes an ablation cut-off based on AWS measured temperature of $0^{\circ} \mathrm{C}$.

Albedo is modelled using a relationship between the natural log of cumulative positive degree-days and albedo measurements made on the glacier. The albedo model is similar to that of Brock and others (2000) and is capable of producing similar results, but at a higher time resolution. For ice, albedo is modelled as having elevation dependence only. The model keeps track of fresh snowfall and adjusts albedo accordingly. 